\title{
Innovating to Improve Access: Changing the Way Courts Regulate Legal Markets
}

\section{Gillian K. Hadfield}

Abstract: The vast majority of ordinary Americans lack any real access to courts as they struggle to navigate a world that is increasingly shaped by legal rules and obligations. Often this means simply forgoing legal rights and entitlements or giving up in the face of claims of wrongdoing. Among those who cannot avoid courts-such as those facing eviction, collection, or foreclosure and those seeking child support, custodial access, or protection from violence or harassment-the vast majority-as many as 99 percent in some cases-find themselves in court without any legal assistance at all. There are many reasons for this lack of meaningful access, including the underfunding of courts and legal aid, but perhaps the most fundamental is the excessively restrictive American approach to regulating legal markets. This regulation, controlled by the American legal profession and judiciary, closes off the potential for significant reductions in the cost of, and hence increases in access to, courts. Unlike the problem of funding, that is a problem that state courts have the power, if they can find the judicial will, to change.

The vast majority of ordinary Americans lack any real access to the legal system for resolving their claims and the claims made against them. Few outside the highest income categories can afford to take their disputes about family, inheritance, neighborhoods, schools, employment, and so on to court; they are left to resolve them as they can through other means. For significant numbers of Americans, not being able to afford legal help means simply "lumping" it, more so than in comparable countries. ${ }^{i}$ Millions of those who cannot avoid court-those who need a divorce or discharge in bankruptcy, for example, or who are facing eviction, foreclosure, garnishment, deportation, fines, or imprisonmentare left to navigate a complex and forbidding process without legal help. As Jonathan Lippman, Chief Judge of the State of New York, notes in his contribution to this issue, in 2010 in New York, for example, 98 percent of tenants facing eviction in housing court, 99 percent of borrowers in consumer credit matters, and 95 percent of parents in child 
support matters were unrepresented; 49 percent of those facing foreclosure (and thus facing a well-represented corporate entity) were unrepresented. ${ }^{\text {ii }}$ In Los Angeles, 90 percent of those in domestic violence matters are unrepresented, as are up to 80 percent of people in landlord/tenant and family cases. The numbers are pretty much the same throughout the country.

Difficulties of access haven't always been with us. In colonial America, local courts were, "on the whole, cheap, informal and accessible." iii Today they are, on the whole, expensive, highly formalized, and effectively unavailable to all but wealthy individuals and businesses. Why is it so expensive to obtain access to the courtroom in America today? Why haven't we invented better, cheaper, more effective ways to deliver on one of the central promises of the rule of law: the promise of a neutral place to take one's disagreements with others?

The reasons for the high cost and inefficiency of modern litigation are multiple. A major problem is that American courts are woefully underfunded and understaffed. On a per capita basis, U.S. public expenditure on courts in 2010 (including the cost of prosecutors, public defenders, and legal aid) was high (\$175) relative to comparable systems in major advanced economies such as the United Kingdom (\$103), Germany (\$127), and France (\$77). But the per capita numbers are misleading. The U.S. system handles a much higher number of cases than these other systems-largely because the U.S. style of government is much more oriented to the use of rights that must be exercised in court than is the case with European regulatory regimes, which rely more heavily on direct regulation. ${ }^{\text {iv }}$ Per capita, the U.S. system (comprised primarily of state courts; federal courts receive a lot of 
scholarly attention, but they account for about 4 percent of all litigation) handles about twice as many cases-civil and criminal-as the United Kingdom and Germany, and three times as many as France. As a result, public expenditure on courts in the United States, per case, is significantly lower: Germany, France, and the United Kingdom spend about 30 percent more on an average per case basis (approximately $\$ 1,475$ ) than the United States does $(\$ 1,115)$. And although the United States has roughly the same number of judges per capita as France and the United Kingdom (approximately 10 for every 100,000 people; Germany has more than twice as many, at 24), these judges are expected to handle much higher numbers of cases. So whereas the United Kingdom has 126 judges per 100,000 cases; France, 205; and Germany, 283, the U.S. system struggles through with just 65.

The fiscal problem, as bad as it is, is only one piece of the picture. Realistically, the likelihood of robust increases in taxpayer support for court budgets in the future is low. For these reasons, it is imperative that we look at the fundamentals: the reasons for the high cost of legal processes and the lawyers needed to navigate them. Here the core problems are twofold: the extraordinary complexity of modern law and process, and the very high cost of obtaining legal assistance in navigating that complexity. Some view both of these features of modern law as inevitable: we live in a complex society, one that requires complex procedures and expensively trained lawyers. But I don't believe either is a given. Indeed, there is tremendous potential for reducing both the complexity and the cost of managing the legal disputes of ordinary people. Achieving that potential, however, requires recognizing that both the problem of complexity and the problem of expensive lawyers are rooted in our excessively restrictive approach to regulating legal 
markets-regulation that is controlled by the American legal profession to a degree that is largely unmatched elsewhere in the developed world, but that is within the power of state courts to change.

The first thing to know about the regulation of legal markets in the United States is that both the right to provide legal goods and services and the rules of operating a legal business are fundamentally controlled by lawyers themselves. Here's how it works in theory in most states: the supreme court of the state decides what constitutes "the practice of law" and then establishes rules, expressed as ethical rules, for how the practice of law is conducted. In practice, the supreme courts of most states delegate or defer to state bar associations to decide these matters, and many state bar associations follow the model rules and policies suggested by the American Bar Association (ABA). The ABA adopts its rules and policies on the basis of majority votes held in its House of Delegates, composed primarily of more than five hundred lawyers who are elected by state and local bar associations. Thus, unless state supreme courts are exceptionally independent of their professional brethren (not a common occurrence, particularly in states with elected judiciaries), the rules governing who can provide legal services and under what terms are determined politically by lawyers' personal preferences and politics. In some cases state legislatures get involved: enacting laws that criminalize the unauthorized practice of law, for example. But the jurisdictional issues are murky: in some cases, such as when legislatures have attempted to expand the right to practice law beyond bar-licensed lawyers, state supreme courts have pushed back, declaring such actions a violation of the 
separation of powers and the courts' inherent and exclusive authority to regulate the practice of law. ${ }^{\mathrm{vi}}$

Of course, there is a built-in danger that a lawyer-controlled process ends up creating legal markets that serve lawyer interests and not the public interest. But even if well-meaning lawyers and judges involved in these processes try to keep the public interest front and center, practically this has not happened and is not likely to happen because the existing providers and their business models are insulated from competition from other potential providers of legal help. More to the point, the regulatory providers themselves are insulated from competition from other regulators who might devise alternative approaches to regulating legal markets.

Insulation from regulatory competition happens in two steps. First, the profession defines the practice of law expansively and in self-referential fashion to mean “everything lawyers do.” This definition includes not only full-scale representation of litigants in court but also anything that might assist those who represent themselves, such as legal advice or help filling out legal documents or forms. Then, having defined the scope of their regulatory authority to reach anything that might be helpful to people involved with legal processes, the legal profession declares that all legal help must be provided by a person who has been licensed by a state bar association. Together, the expansive definition of the practice of law and the decree that only attorneys who comply with bar association rules may engage in the practice of law establishes lawyers as the exclusive source of regulatory authority-controlling everything about how any aspect of legal assistance is provided. 
One way of thinking about why such a system promotes complexity and high costs is to focus on the role of monopoly here. Lawyers own the whole market, they don't have to share it with anyone, and they can therefore extract the full value from it. This is the line of thinking that supposes that state bar associations drive up lawyers' fees by limiting the supply of lawyers, and that lawyers, with the keys to the courthouse, can extract whatever the market will bear. It is also the line of thinking that supposes that lawyers have an incentive to make things more complex than they have to be in order to create more work and therefore more billings for themselves.

But we don't need to go so far as to assume that lawyers and judges are acting in deliberately greedy ways to reach the conclusion that what stands in the way of reducing the cost and complexity of access to American courts is the way in which the legal profession controls the regulation of legal markets. Even if judges and lawyers are honestly concerned (as many are) about the high cost of legal access, and even if the complexity of legal processes and rules is just a systemic response to the complexity of modern life (as many surely believe), the regulatory system that the legal profession implements in good faith nonetheless stands as a central barrier to reducing cost and complexity. The reason is that this approach to regulation creates an environment that is exceedingly hostile to innovation and the creation of better, less expensive ways of connecting people to courts. Yes, there may be substantial pressure for law and process to become ever more complex in a complex world; and yes, navigating complexity may require ever greater levels of expensive specialization and expertise. ${ }^{\text {vii }}$ But the question is why legal markets are not changing to develop smart ways of responding to complexity in less complex and less expensive ways. Think about the smartphone in your pocket or 
purse: it navigates an environment that is constantly ratcheting up in terms of complexity. Yet it does so in ways that grow ever simpler, more elegant, and less costly. Why doesn't that happen in our court systems?

Innovation feeds on two key ingredients: creative thinking and a willingness to put time and money behind risky new ideas. But the regulatory environment created by the profession stymies its ability to secure either. First, the way in which legal markets are regulated makes them highly insular echo chambers. Everyone who can participate in providing legal services is trained in the same way, and spends most of their time interacting with professionals just like themselves. This limits the likelihood that new ideas will emerge. Imagining that it is likely that a process that involves lawyers talking only to other lawyers will give birth to fundamentally new means of accomplishing longheld objectives is like imagining that librarians, whose job after all is advising on how to find information, would have eventually invented Google.

Second, professional regulations prohibit those lawyers who do have new ideas from accessing the capital necessary to support the long journey from idea to implementable innovation. In my experience, lawyers routinely underestimate the significant up-front investment in time, trial, and error required to get a truly new business model off the ground. Most of our dramatic innovations in technology and the Internet took a long time to iron out the details. Few were initially imagined to work the way they do now. Facebook started out as a way for college students to meet each other on campus, not as the global platform for all manner of social, political, and commercial interactions that it is today. Twitter, which has transformed commercial media, began as a 
way for friends to share status updates. Despite their transformative impact on our world, both needed huge amounts of investment to support their operations as the two companies figured out who and what they were. We should not expect new models of legal services to help people navigate courts at lower cost to be assembled on the cheap. But professional regulation in law prohibits innovators in law from accessing any investment capital beyond what they can extract from other lawyers. That cuts off legal innovation, such as it is, from the sources of funds-angel investors, friends and family, venture capital, private equity, public capital markets-that fuel innovation everywhere else in the economy. ${ }^{\text {viii }}$

Without access to fresh thinking from outside the echo chamber of legal debates, and without the capital needed to test new and risky ideas, innovation in the legal profession has foundered. Confronted with the problem of access to courts, almost all lawyers start thinking in the same way: how can we get more lawyers for those in need? The ideas that emerge end up forming a short list: increase legal aid, increase pro bono work, and secure a statutory or constitutional right to civil legal representation-a civil Gideon to parallel the right to counsel for the criminally accused facing risk of imprisonment. ${ }^{\mathrm{ix}}$ There is no doubt that increased legal aid, pro bono work, and expanded rights to publicly funded legal counsel are an important part of what we need to do to improve the functioning and fairness of our legal systems. But the stark reality is that none of these conventional solutions can make any serious dent in the problem. Providing even one hour of attorney time to every U.S. household facing a legal problem would cost on the order of $\$ 20$ billion. Total U.S. expenditures on legal aid, counting both public and charitable sources, are just 5 percent of that amount, or $\$ 1$ billion. Even if 
lawyers became more willing to work for free, U.S. lawyers would have to increase their pro bono work from an annual average of thirty hours each to over nine hundred hours each to provide some measure of assistance to all households with legal needs. ${ }^{x}$ That's pushing toward half a year's worth of billable hours for the average lawyer. That will never happen.

\section{$* * *$}

What would people outside the legal echo chamber think up if presented with the problem of reducing the cost and complexity of helping people navigate court claims? We don't have to venture too far into the fantasy world to know the answer to this question; we just need to look at what emerges in an environment-namely, the United Kingdom-where innovative thinking and risk-taking in the context of legal problems are not the exclusive preserve of lawyers. Here we see significant levels of innovation, not all of which survive market tests-emphasizing the need for the kind of risk capital that underwrites innovation in other sectors. In the legal sector in the United Kingdom, the solutions that the market has attempted include:

- A co-op grocery chain with annual sales of $£ 13.5$ billion providing legal services along with other services, such as banking, insurance, travel, funeral, and pharmacy, online and in stores. ${ }^{\mathrm{xi}}$

- An online divorce service that provides graduated flat-fee services beginning with simple document completion and ascending to increasing levels of drafting, phone and email assistance from licensed solicitors, and legal opinions from barristers; litigants can represent themselves using these services or opt for a divorce managed entirely by lawyers and managed through the Web. ${ }^{\text {xii }}$ 
- A major bank operating a legal document service that provides a means both to create online documents such as wills, powers of attorney, and trusts and to obtain lawyer-drafted demand letters to resolve issues such as problems with credit ratings, household repairs, and consumer goods. Users complete an online questionnaire for a customized document, and then can choose to submit the document as is, have it reviewed by an internal team of legal experts, or have it reviewed by lawyers in an external law firm, all for flat fees paid to the online company. ${ }^{\text {xiii }}$

- A national chain of lawyers' offices operating under an umbrella brand name and shared customer service protocols, supported by kiosks in retail bookstores, a consumer-friendly website providing free, easy-to-understand legal information and a free initial consultation. ${ }^{\text {xiv }}$

- A franchise system offering small firm practitioners a "business in a box"software and procedures for setting up and operating a law office-and affiliation with a national brand focused on using standardization, technology, common marketing, and customer-focused business practices to reduce costs and increase quality. ${ }^{\mathrm{xv}}$

- A nonprofit membership organization for small businesses that includes unlimited legal advice, documents, and insurance that covers legal costs for pursuing or defending legal claims, up to $£ 50,000$ per incident, all as a benefit of membership for a flat annual fee..$^{\mathrm{xvi}}$ 
- Online subscriber services that provide unlimited phone and email advice for legal, financial, and other consumer problems, tailored to the user's specific circumstances, for a single annual fee. ${ }^{\text {xvii }}$

If you are not an American lawyer, these may not sound like amazing innovations. Indeed, outside of legal markets, these are the kinds of services that are available in most markets in the Web-enabled twenty-first century, powered by technology, consumer research, Internet-based platforms, the advantages of a large customer base, and creative ways of cutting the costs of standardized consumer products. The sad fact is that none of these relatively simple innovations in legal services is currently possible in the United States. Each, in one way or another, violates U.S. legal professional regulations. $^{\text {xviii }}$

- Most of these entities operate as for-profit or nonprofit businesses that are owned, managed, or financed in significant part by non-lawyers, which violates U.S professional rules. The online divorce company was founded by a former paralegal with expertise in family law. The franchise company was organized as a partnership with a legal software company; and the company providing an umbrella brand is financed with private equity. The subscription services company is a nonprofit company that also engages in consumer advocacy and publishes reviews of consumer products.

- Some of these entities are licensed as organizations authorized to provide legal services. The co-op grocery stores, for example, were the first "alternative business structures" licensed to provide legal services in the United Kingdom. Only individual lawyers can be licensed in the United States. 
- All of these new providers supply a uniform product across a national market. Product uniformity is hampered in the United States because a lawyer licensed under state-based rules must supply any services accessed by individuals in a particular state.

- Most of these entities depend on the use of legal experts who are not traditionally qualified lawyers to supply legal services at low cost, such as paralegals and licensed Legal Executives (who have to complete a community college degree and spend a period of years under solicitor supervision before practicing independently). Documents purchased with "legal review" but not "lawyer review" from the document provider are reviewed by in-house legal experts, but not necessarily solicitors.

- The barristers and solicitors who provide legal services through these companies are either employed by the company or paid out of fees collected by the company from clients. The franchise and branding organizations collect the equivalent of royalties on revenues earned by the law firms that sign up with them. In the United States, lawyers are not permitted to be employees of non-lawyer-owned or -managed entities. The contract payment or royalty mechanisms used would, under most states' professional regulations, constitute either impermissible feesharing with a non-lawyer or impermissible payment of referral fees to a for-profit entity.

- Many of these entities integrate a variety of services in addition to legal services, requiring the management guidance of non-lawyer professionals such as finance, tax, consumer, and employment experts. In the United States, 
any entity that attempts to integrate services must be owned, managed, and financed exclusively by lawyers; other professionals can participate in the business only as employees of lawyers.

The United Kingdom has its own problems with access to justice. In recent years there have been major cuts to a formerly generous legal aid system that in its heyday in the late 1970s was available to almost 80 percent of all households; eligibility had fallen below 30 percent by 2007 and is expected to drop further. Whereas the original legal aid schemes in the United Kingdom covered almost all civil and criminal matters, recent reforms have eliminated major categories such as divorce and custody, immigration, and personal injury and restricted the scope of assistance available for employment, education, debt, housing, and benefits matters. Nonetheless, the U.K. system faces these new limitations on legal aid-the availability of which still far outstrips U.S. public funding for legal assistance ${ }^{\mathrm{xix}}$-in the context of a professional regulatory scheme that facilitates innovation of new solutions for access. Relatively low-cost online assistance with divorce matters, for example, is likely to fill at least some of the gap left by elimination of most of these matters from the legal aid scheme.

It is not hard to imagine what kind of impact services like those already available in the United Kingdom could have on the crushing problem of the cost of navigating American courts. Easy access to "lawyer letters" to resolve disputes before they are filed in court could both provide an avenue of recourse for those who cannot afford to go to court and reduce the number of claims that end up in courtrooms. Providing assistance with the completion of forms, drafting of motions or papers, and/or unlimited phone and email assistance to someone who is working his or her way through a housing, 
bankruptcy, immigration, or family matter, for example, could substantially reduce the errors and misunderstandings that clog dockets, frustrate clerks and judges, and trip up laypeople. The U.K. divorce service mentioned above offers exactly this kind of low-cost help: for $£ 199$, a customer seeking a change in a child or spousal support order can arrange online for a licensed solicitor to draft the appropriate motion and accompanying affidavit and then receive unlimited phone and email support from a solicitor up through the hearing on the matter.

This kind of service is only possible for a low flat fee, however, if the entity supplying the service 1) can attain sufficient national scale to smooth out the high-need and low-need cases; 2) can employ legal professionals other than lawyers when providing standardized assistance according to lawyer-generated protocols; and 3) has sufficient access to diversified capital markets to secure the funds needed to invest in the building of a large customer base, and developing easy to comprehend instructions, reliable protocols, appropriate pricing, and a user-friendly interface. The only reason we do not have a comparable service now in the United States is that the current regulatory structure stands in the way of achieving all three of those requirements for innovation.

The way to reduce the cost and complexity of accessing courts is to harness the same mechanisms that reduce costs in other areas: standardization, scale, analysis of data, design, experimentation, and specialization. ${ }^{\mathrm{xx}}$ Lawyers do not need to do everything: find the clients, run the business, design the website, develop customer relations expertise, find the other experts, collect the fees, experiment with new methods, provide the investment capital, implement standardized protocols, and so on. But our current 
regulatory system requires them to do it all, and this plays a substantial role in keeping hourly rates for legal help high.

There are few sectors of the legal market that are more competitive than the lower end of the personal services market; there is no shortage of lawyers anxious to serve the people who are struggling through court processes alone. That fact tells us that the fees these lawyers are charging-on the order of \$250 an hour-are probably close to rockbottom for the business model in which these lawyers practice. That model requires lawyers operating a solo or small firm practice to charge enough to run the risk of not finding or collecting from clients: they lack the scale to smooth those risks and the capacity for investing in marketing, quality control, and customer service protocols to improve profitability. Most of them end up taking home far less than the $\$ 250$ per hour that they charge. We know that many of the lawyers practicing in this sector of the market would be willing to work for a stable income that averages about \$30-40 an hour-\$60,000-70,000 a year-or less. We know this because that's the going rate for contract attorneys-who supply legal expertise and nothing more. ${ }^{\mathrm{xxi}}$

To reduce the cost of helping people access courts we need to change the business model. And, frankly, that's not hard to do. There are U.S. companies that already have this business model; some of them are already operating independently or in joint ventures with U.K. companies in the United Kingdom's more open market. They are ready to make significant leaps forward in harnessing technology and broad-based customer service organizations to support the millions of litigants who, of necessity, have to navigate court without conventional legal representation. LegalZoom, ${ }^{\text {xxii }}$ RocketLawyer, and Law Depot have built recognized legal brands and large-scale 
platforms that provide ordinary consumers with a low-cost means of completing the documents necessary to make a will, file a simple divorce, obtain a trademark, or incorporate a company. Current regulations restrict them to serving only as a "scrivener," filling in the blanks of legal forms; any substantive legal assistance has to be arranged through a legal plan that connects users to private attorneys and is limited to thirty minutes of advice per matter before a regular attorney/client fee arrangement kicks in. But these services could do so much more. They are well positioned to move quickly into the space of providing substantive support to people filing court documents and participating in court proceedings.

Other services such as Pearl ${ }^{\mathrm{xxiii}}$ and LawGuru provide a platform for purchasing answers to legal questions. Currently these systems are restricted in various ways: providing generic legal information that is not tailored to the circumstances of the questioner or requiring a more cumbersome process of connecting a questioner to a local lawyer and a complicated consent form from the questioner to authorize limited help. But these systems, designed to provide low-cost rapid responses in real-time with attorneys, could easily scale up to provide more tailored advice and support for litigants facing immediate questions about how to respond to legal documents, the progress of a hearing, and so on. Imagine how much more effective this kind of system could be, installed as kiosks in courthouses throughout the country, than an overburdened clerk's window or a poorly funded and overwhelmed self-help center.

These are just some of the possibilities that could be online and available to Americans in short order. Other possibilities lie on the horizon, particularly ones that involve reconfiguring how cases are received, processed, and handled by courts. While 
the creation of online claims filings and hearings, for example, could be implemented by individual court systems now, using public dollars, any significant roll out of such systems almost certainly depends on recruiting private companies to develop and deliver them, because they require investment, risk capital, and the kinds of business and technology expertise that lie outside of the domain of lawyerly expertise. Partnerships and contracts with entities to provide low-cost systems for delivering court services are not difficult to imagine or realize, if only we could break out of the existing regulatory framework.$$
* * *
$$

I know what the major objection from the profession will be to these ideas: What about quality? What about protecting the public from unqualified scam artists? But this worry itself is also one that is blinkered by the confines of conventional ideas about legal help. It imagines that the alternative to a qualified lawyer providing legal help one-on-one in small and solo practice settings is an unqualified non-lawyer providing legal help one-onone in a small or solo practice setting. The short answer to the challenge often is: something is better than nothing, and currently nothing is what the vast majority of people who need access to our courtrooms get. That's not a bad answer, but there is a better one.
}

The better answer is to recognize that a change in the business model of how legal help is provided introduces the potential for changes in the regulatory model. The current regulatory model purports to protect people by requiring everyone who provides any legal help to obtain a J.D. and a license and to follow rules set by state bar associations. But there are other, better ways to protect people. 
A more robust regulatory model would recognize that quality can be supported in many ways. A business model built on the delivery of legal help by organizations that develop broad-based platforms operating at large scale secures quality in large measure through standardization and organizational protocols. Instead of thousands of individual lawyers in their offices deciding what is a good response to a particular one-off problem, or even an anecdotal sample of legal problems, an organization asks legal experts to collaborate on developing a protocol for common problems and circumstances; scale, technology, and data analysis allow the organization to extend protocols to less-common (but sufficiently frequent) problems. The organization pilots those protocols, collecting data internally and from users to assess how reliably the protocol is understood and implemented (which requires compliance not only by employees but also by the users themselves). It uses that data to refine the protocol. It puts in place auditing and oversight mechanisms to ensure the protocol is followed. It identifies the cases that are not well handled by standard protocols, and elevates them to more customized (and expensive) treatments or refers them outside to other providers. If the protocol fails, the organization bears the liability-commercial and legal-for those failures. And if, as should be the case, the organization is itself dependent on a license to provide legal assistance, the organization runs the risk of losing its license if its procedures fail to provide adequate legal assistance as promised.

Quality in this organizational model is a product of the system instead of a single individual operating in isolation. And that is a far better guarantee of systematic quality than individual licensing. It is true that organizations can fail to deliver quality as promised because they are poorly run or overly bureaucratic. They can fail because they 
are tempted under competitive and/or stakeholder pressure to cut corners or mislead their users about what they can actually do for them. But lawyers operating in solo and small firm settings can also fail in many of the same ways: making mistakes, letting personality get in the way, overbilling, misleading, taking on more than they can handle, doing shoddy work. The advantage of the organizational model is that it is far easier to detect, regulate, and correct the organization's failures. It is easier to identify systemic problems when you have enough data to look at. It is easier for a regulator to oversee a few organizations instead of thousands of individuals. It is easier for consumer watchdogs to monitor the quality of an organization that serves thousands of users nationally than to monitor thousands of providers who serve a handful of users in a local market. It is easier for users to obtain reliable information about quality from other users about an organization that delivers a standardized service on a large scale than it is for them to discover anecdotes about a local provider's performance.

The path to greater innovation in the ways people obtain the legal help they need to access and navigate our courts clearly requires change to the way in which the business of law is regulated. Unfortunately, the path to that regulatory change has proven a lot harder to discern. Other professions, such as medicine, traditionally enjoyed selfgovernance as a matter of delegation from state legislatures. Reform in those professions has come about largely through legislative means at both the state and federal level.

The basis of legal professional regulation, however, is a murky mess. It results from a complex and poorly understood mélange of express state constitutional provisions, state supreme courts' claims to inherent constitutional authority, state statutes, court 
rules, judicial opinions, and bar association ethics codes and disciplinary committee opinions. A federal solution seems ideal, particularly in light of the importance of increased scale to reduce costs. But states have historically been responsible for creating and operating the courts that manage almost all of the country's litigation, and there are reasonable claims to constitutional authority to continue to regulate the profession locally.

The prospect of working state by state to change the regulatory approach is, however, daunting to say the least. Bar associations wield significant political and practical influence over professional rulemaking; indeed, in most states it is simply taken for granted that the bar associations are the rulemakers. State supreme courts often lack the awareness, much less the wherewithal, to assert a serious role in professional regulation; they are working overtime simply to stay afloat in a sea of unrepresented litigants and struggling with dwindling budgets that force them to close their courtrooms and eliminate staff. ${ }^{\text {xxiv }}$ Legislatures can act, but if they upset bar associations, those bar associations can and do challenge legislation as unconstitutional on separation of powers grounds.

Some state supreme courts, precisely because they stand at the headwaters of the deluge of unrepresented litigants in courts, are beginning to test their capacity to roll back the excessive limitations that have accumulated on legal markets. The Washington State Supreme Court was the first in the nation, in 2012, to order the state bar association to create a scheme to license a new category of legal assistants to provide a limited set of legal services, such as review of documents and assistance with understanding and navigating court procedures. ${ }^{\mathrm{xxv}}$ The Board of Trustees of the California State Bar, which 
is constitutionally created as a branch of the judiciary, ${ }^{\mathrm{xxvi}}$ is exploring the potential for introducing a limited licensing scheme. ${ }^{\text {xxii }}$ New York's Chief Judge Jonathan Lippman, as he reports in his contribution to this issue, has tasked a working group with creating a pilot program to explore the possible roles that limited license professionals might play in helping overcome the crushing load of unrepresented litigants in New York courts. These judicial efforts suggest a promising trend.

As law and legal process have become more complex, as legal rights and duties have become more pervasive, the idea that ordinary citizens can secure due process without any legal help is increasingly untenable. The path to progress may thus have begun to emerge from the fog: courts have the power to say from whom and how the millions who appear before them without lawyers can secure the legal help they need. And if, as is overwhelmingly the case, our existing regulatory scheme has resulted in a system in which lawyers' help lies beyond the reach of the ordinary citizen, then it is within the power-and the duty-of courts to expand access to justice by expanding access to other sources and types of legal help. The innovators for law are just waiting for the call.

Gillian K. Hadfield is the Richard L. and Antoinette Schamoi Kirtland Professor of Law and Professor of Economics at the University of Southern California. Her publications include recent articles in such journals as Law \& Ethics of Human Rights, Journal of Legal Analysis, Journal of Law and Courts and International Review of Law and Economics. Her latest book project is Law for a Flat World: Reinventing Legal Infrastructure for the New Economy (forthcoming, Oxford University Press).

\footnotetext{
${ }^{\mathrm{i}}$ For estimates of the rates at which people in different countries "lump" their potential legal problems by taking no steps to address them, see Gillian K. Hadfield and Jamie Heine, "Life in the Law-Thick World:
} 
The Legal Resource Landscape for Ordinary Americans," forthcoming in Beyond Elite Law: Access to Civil Justice for Americans of Average Means, ed. S. Estreicher and J. Radice (Cambridge University Press).

ii Task Force to Expand Access to Civil Legal Services in New York, Report to the Chief Judges of the State of New York, November 2010.

iii Lawrence M. Friedman, A History of American Law (New York: Simon \& Schuster, 2005), 11.

${ }^{\text {iv }}$ For an analysis of this phenomenon, see Robert A. Kagan, Adversarial Legalism: The American Way of Law (Cambridge, Mass.: Harvard University Press, 2001).

${ }^{v}$ See Hadfield and Heine, "Life in the Law-Thick World."

${ }^{v i}$ See, for example, Merco Construction Engineers Inc. v. Municipal Court 21 Cal.3d 724 (1978) (statute authorizing corporation to appear in court through non-attorney corporate employee violates separation of powers). See also In re Attorney Discipline System 19 Cal.4th 582 (1998) (California State Bar is constitutionally created entity subject to court's primary, inherent authority over admission and discipline of attorneys and retains the power to impose fee on attorneys to fund disciplinary system despite Governor's veto of legislation imposing fee and legislative inaction); and In re New Hampshire Bar Association, 855 A.2d 450, 451, 456 (N.H. 2004) (statute requiring state bar to be bound by results on referendum asking whether state bar should be unified or not unconstitutional). The Missouri Supreme Court has been particularly clear on the inherent and primary power of courts to determine what constitutes the practice of law: "We have generally recognized that the legislature may, in the exercise of the police power, aid the court by providing penalties for unauthorized practice of law, but that it may in no way hinder, interfere with or frustrate the court's inherent power. We have at times recognized and used the statutory definition [of the unauthorized practice of law] ... we may undoubtedly do so reserving the right, however, at all times to fix our own boundaries and declare our own restrictions in all matters other than a prosecution under the statute." See Hoffmeister v. Tod, 349 S.W.2d 5, 11 (1961).

${ }^{v i i}$ For a discussion of the inherent tendencies toward complexity and specialization in law and the impact on the cost of lawyers, see Gillian K. Hadfield, "The Price of Law: How the Market for Lawyers Distorts the Justice System,” Stanford Law Review 98 (2000): 953-1006.

viii See Gillian K. Hadfield, "Legal Barriers to Innovation: The Growing Economic Cost of Professional Control over Corporate Legal Markets," Stanford Law Review 60 (2008): 1689-1732.

ix The concept of "civil Gideon" gained currency in the late 1980s. See American Bar Association Consortium on Legal Services and the Public, Civil Justice: An Agenda for the 1990s (1991).

${ }^{\mathrm{x}}$ These calculations are based on the evidence from ABA and state bar association surveys between 1995 and 2010 showing that roughly half of U.S. households are experiencing an average of two legal problems at any given time. That's 115 million legal problems. At an average of $\$ 200$ an hour, that's over $\$ 20$ billion for one hour of help. If the 1.25 million American lawyers are providing help for an average of three problems (average pro bono hours according to the ABA are 30, and I conservatively assume 10 hours per problem), that amounts to 3 percent of total need.

${ }^{\mathrm{xi}} \mathrm{http}: / /$ www.co-operative.coop.

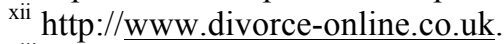

xiii $h t t p: / /$ www.halifaxlegalexpress.co.uk. This service was provided through an outsourcer, Epoq Legal.

Halifax Bank discontinued the services in October 2013, directing consumers to http://www.mylawyer.co.uk, a comparable service also delivered through Epoq.

${ }^{x i v}$ http://www.qualitysolicitors.com. Quality Solicitors discontinued its placement of kiosks in retail bookstores in late 2013.

${ }^{x v} \mathrm{http} / / / \mathrm{www}$. face2facesolicitors.net. Face2Face went out of business in early 2014.

${ }^{\text {xvi }}$ http://www.fsb.org.uk.

xvii $h t t p: / /$ www.whichlegalservice.co.uk.

xviii For a discussion of how proposals to allow such business structures in the United States have died because they were voted down among lawyers, see Gillian K. Hadfield, "The cost of law: Promoting access to justice through the (un)corporate practice of law," International Review of Law and Economics (forthcoming).

${ }^{x i x}$ In 2012, legal aid per capita in the United Kingdom was five times the level in the United States; measured on a per case basis (that is, taking into account that many more matters are handled through courts in the United States than is the case in most other countries), the level of legal aid in the United 
Kingdom is more than ten times the levels of U.S. funding. See Hadfield and Heine, "Life in the LawThick World."

${ }^{\mathrm{xx}}$ For an extended analysis of the economics of legal businesses, see Hadfield, "The cost of law."

${ }^{\mathrm{xxi}} \mathrm{http} / / / \mathrm{www} . c r a i n s n e w y o r k . c o m / a r t i c l e / 20120108 /$ SMALLBIZ/301089988.

xxii I serve on the Legal Advisory Council of LegalZoom.

xxiii I serve on the Advisory Board of Pearl.

${ }^{x x i v}$ For evidence of the impact of budgetary cuts in California, see the Honorable Barry Goode, Summary of Impacts from Instant Survey (March 11, 2013), http://www.courts.ca.gov/partners/documents/20130312PJ-Instant-Survey-Impacts.pdf.

$\frac{\mathrm{xxv}}{\mathrm{x}}$ See Brooks Holland, "The Washington State Limited License Legal Technician Practice Rule: A National First in Access to Justice," http://papers.ssrn.com/sol3/papers.cfm?abstract id=2196607.

xxvi In re Attorney Discipline System: Requests of the Governor and The State Bar of California 19 Cal.4th $582(1998)$.

${ }^{x x v i i}$ http://board.calbar.ca.gov/docs/agendaItem/Public/agendaitem1000010722.pdf. 